\title{
Impact of heat stress, nutritional stress and their combinations on the adaptive capability of Malpura sheep under hot semi-arid tropical environment
}

Vijai Prakash Maurya - Veerasamy Sejian •

Davendra Kumar - Syed Mohammad Khursheed Naqvi

\begin{tabular}{|c|c|}
\hline 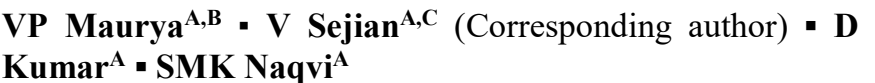 & $\begin{array}{l}\text { BIndian Veterinary Research Institute, Izatnagar, Bareilly- } \\
\text { 243122, Uttar Pradesh, India. }\end{array}$ \\
\hline $\begin{array}{l}{ }^{A} \text { Central Sheep and Wool Research Institute, Avikanagar, } \\
\text { Rajasthan-304501, India. } \\
\text { email: drsejian@gmail.com }\end{array}$ & $\begin{array}{l}{ }^{\mathrm{C}} \text { National Institute of Animal N } \\
\text { Adugodi, Bangalore-560030, Karna }\end{array}$ \\
\hline
\end{tabular}

Received: April 24, 2018 • Revised: August 09, 2018 • Accepted: August 09, 2018

\begin{abstract}
A study was conducted to assess the cumulative effects of combined stresses (heat and nutritional) on physiological adaptability, blood biochemical and endocrine responses in Malpura rams. The study was conducted for a period of 45 days. Twenty eight adult Malpura rams (average BW $66.0 \mathrm{Kg}$ ) were used in the present study. The rams were divided into four groups viz., $\mathrm{CON}$ ( $\mathrm{n}=7$; control), HS $(\mathrm{n}=7$; heat stress), NS ( $\mathrm{n}=7$; nutritional stress) and CS $(\mathrm{n}=7$; combined stress). The animals were stall fed with a diet consisting of $60 \%$ roughage and $40 \%$ concentrate. The CON and HS ewes were provided with ad libitum feeding while NS and CS rams were provided with restricted feed (30\% intake of GI ewes) to induce nutritional stress. The HS and NS rams were kept in climatic chamber @ $42^{\circ} \mathrm{C}$ and 55\% RH for six hours a day between 10:00 hr to 16:00 hr to induce heat stress. The parameters studied were respiration rate (RR), pulse rate (PR), rectal temperature (RT), scrotal volume, sweating rate scrotum, sweating rate skin, haemoglobin $(\mathrm{Hb})$ and packed cell volume (PCV), plasma cortisol, $\mathrm{T}_{3}$ (tri-iodo-thyronine), and $\mathrm{T}_{4}$ (thyroxin) level. Combined stresses significantly $(\mathrm{P}<0.01)$ influenced all adaptive parameters studied. The study shows that Malpura rams possess the adaptive capability to two stresses simultaneously. This is evident from the nonsignificant changes in RR, RT, sweating rate of scrotum and skin and $\mathrm{Hb}$ concentration between $\mathrm{HS}$ and CS groups. Further, the capability to adjust the cortisol level to minimum possible increase to elicit the heat stress relieving effects also proves the superior adaptive capability of Malpura rams to the effects of combined stresses.
\end{abstract}

Keywords: cortisol, combined stress, heat stress, nutritional stress, Malpura rams, physiological response, thyroxin

\section{Introduction}

Livestock production is the thought to be the world's dominant land use activity, covering about 45 per cent of the earth's land surface, much of it in harsh and variable environments that are unsuitable for other uses. Climate change could impact the amount and quality of produce, reliability of production and the natural resource base on which livestock production depends. Climate is an important factor of agricultural productivity. The changing climate is expected to have severe impact on livestock production systems across the world.

Global climate change is expected to alter temperature; precipitation, atmospheric carbon dioxide levels, and water availability which will intern affect the productivity of crop and livestock systems (Hatfield et al 2008). Climatic change could increase thermal stress for animals and thereby reduce animal production and profitability by lowering feed efficiency, milk production, and reproduction rates (St-Pierre and Schnitkey 2003).

Apart from heat stress, livestock also are affected by other environmental stresses like nutritional stress, water nonavailability and walking stress in extensive system of rearing (Sejian et al 2011; Sejian et al 2013). Therefore livestock researchers aiming at improving livestock production under changing climatic scenario must aim at counteracting multiple stresses as these stresses are common occurrences in most ecological zones where livestock are reared (Sejian et al 2010). Under the changing climatic scenario, the concept of multiple stresses emerges as a potential threat to livestock production and its survival (Sejian et al 2010; Sejian et al 2011). Hence research efforts need to be prioritized to tackle multiple stresses simultaneously to improve the economy of the livestock farms (Sejian et al 2013).

Generally when animals are exposed to one stress at a time, they can effectively counter them based on their stored body reserves without altering the normal body functions. However, if they are exposed to more than one stress at a time, the summated effects of the different stressors might prove detrimental to these animals (Sejian et al 2011). This is 
because of their inability to cope with the combined effects of different stressors simultaneously. In such a case, the animal's body reserves are not sufficient to effectively counter such environmental extremes (Sejian et al 2013). As a result their adaptive capability are hampered and the animals struggle to maintain normal homeothermy. Moberg (2000) explained that when animals are exposed to only one stress, they may not require the diversion of biological resources needed for other functions. If, however, two of these stressors occur simultaneously, the total cost may have a severe impact on other biological functions. As a result their normal basal functions are drastically affected leading to lowering of production.

There are no reports on the influence of heat stress on the adaptive responses when coupled with long term nutritional stress in rams. This is very important since both adaptive capability and level of nutrition available to the animals decides their productive and reproductive efficiency (Sejian et al 2010; Sejian et al 2011). In addition, despite the general awareness that energy demands vary between different seasons, only few quantitative data exist relating environment, nutrient need and productive efficiency (Sejian et al 2011). Hence, the study was conducted to observe the impact of two environmental stresses (heat and nutritional) simultaneously on the physiological adaptability, blood biochemical and endocrine responses in adult Malpura rams of hot semi-arid environment.

\section{Materials and Methods}

Site of study

The experiment was carried out at Central Sheep and Wool Research Institute farm, which is located in the semiarid region of the country at longitude $75^{\circ} 28^{\prime} \mathrm{E}$ and the latitude of $26^{\circ} 26^{\prime} \mathrm{N}$ and at altitude of $320 \mathrm{~m}$ above mean sea level. The average annual maximum and minimum ambient temperature ranges between 6 to $46{ }^{\circ} \mathrm{C}$. The mean annual relative humidity ranges between 20 to $85 \%$. The annual rainfall in this area ranges from 200 to $400 \mathrm{~mm}$ with an erratic distribution throughout the year. The study was conducted during summer season (April-May). The mean environmental temperatures, relative humidity and wind velocity during the study period (45 days) were depicted in Table 1.

Table 1 Mean and SEM of Meteorological data during the study period.

\begin{tabular}{lcccccc}
\hline Time of Recording & $\begin{array}{c}\text { Minimum } \\
\text { temperature } \\
\left({ }^{\circ} \mathrm{C}\right)\end{array}$ & $\begin{array}{c}\text { Maximum } \\
\text { temperature } \\
\left({ }^{\circ} \mathrm{C}\right)\end{array}$ & $\begin{array}{c}\text { Dry bulb } \\
\text { temperature } \\
\left({ }^{\circ} \mathrm{C}\right)\end{array}$ & $\begin{array}{c}\text { Wet bulb } \\
\text { temperature } \\
\left({ }^{\circ} \mathrm{C}\right)\end{array}$ & $\begin{array}{c}\text { Relative } \\
\text { Humidity } \\
(\%)\end{array}$ & $\begin{array}{c}\text { Wind } \\
\text { velocity } \\
(\mathrm{m} / \mathrm{sec})\end{array}$ \\
\hline Morning (8:00 hrs) & $17.5 \pm 0.28$ & $27.50 \pm 0.35$ & $22.92 \pm 1.04$ & $13.88 \pm 0.47$ & $50.43 \pm 4.08$ & $4.0 \pm 0.64$ \\
Afternoon (14:00 hrs) & $26.72 \pm 0.33$ & $33.08 \pm 0.52$ & $27.47 \pm 1.28$ & $16.50 \pm 0.88$ & $33.25 \pm 2.54$ &
\end{tabular}

The values are averages of 45 days study period.

\section{Animals}

Malpura is a triple purpose hardy sheep breed, which originated in the arid and semi-arid areas of Western tropical India. Twenty eight adult Malpura rams (2-4 year old) with mean body weight of $66.00 \pm 1.65 \mathrm{~kg}$ were used in the study. The animals were housed in well-ventilated sheds made up of asbestos roofing at the height $2.4 \mathrm{~m}$ and open from side and maintained under proper hygienic conditions. The animals had ad libitum access to good quality drinking water. Prophylactic measures against sheep diseases like sheep pox, peste des petits ruminants, enterotoxaemia, endo and ectoparasitic infestations were carried out as prescribed by the health calendar of the institute to ensure that the animals were in healthy condition throughout the study.

\section{Climatic chamber details}

The size of the climatic chamber is 12,8 and $7 \mathrm{ft}$ for length, width and height respectively. The chamber has the provision to alter the temperature and the relative humidity ranging between -5 and $60{ }^{\circ} \mathrm{C}$ and $1 \%$ and $100 \%$ respectively. All sides of the climatic chamber are made up of stainless steel. The chamber has the programmable temperature and humidity regulator to maintain the ideal temperature and humidity as per the requirement of the experiment. The climatic chamber has the provision to hold fourteen animals at a time. The animals were acclimated for a period of 15 days to the climatic chamber prior to the start of the experiment.

\section{Experimental design}

The present study was conducted for a period of 45 days. Twenty-eight adult Malpura rams (average BW 66.0 Kg) were used in the present study. The rams were randomly divided based on body weight into four groups viz, $\operatorname{CON}(n=7$; Control), HS ( $n=7$; heat stress), NS ( $n=7$; nutritional stress) and CS ( $\mathrm{n}=7$; Combined stress). All the animals were stall fed with a diet consisting of $70 \%$ roughage and $30 \%$ concentrate. The CON and HS rams were provided with ad libitum feeding while NS and CS rams were provided with restricted feed ( $30 \%$ of intake of CON rams) to induce nutritional stress. The forage and concentrate were mixed in appropriate proportion and offered twice daily at $800 \mathrm{~h}$ and $1600 \mathrm{~h}$ for CON and HS groups while for NS and CS group the $30 \%$ feed was split into two portion and offered twice daily. It has been established in 
semi-arid tropical environment that nutritional stress to the tune of only $30 \%$ ad libitum are available for the small ruminants reared in extensive system. Hence attempts were made to study the influence of only $30 \%$ of ad libitum feeding to simulate the condition as that would appear in natural environment. Similar such attempts were already established in sheep from the same laboratory (Sejian et al 2010). This feeding schedule began two months before the start of actual experiment in order to ensure exposure to double stresses (thermal and nutritional) simultaneously in CS rams and only nutritional stress in NS rams. The HS and CS rams were kept in climatic chamber at the constant temperature of $42^{\circ} \mathrm{C}$ and relative humidity of $55 \%$ for six hours a day between $10: 00 \mathrm{~h}$ to $16: 00 \mathrm{~h}$ to induce heat stress. This treatment protocol was followed for all 45 days study period. Physiological responses were recorded twice daily ( $800 \mathrm{~h}$ and $1400 \mathrm{~h}$ ) on days 0,15 , 30 and 45 of the study. Blood samples were also collected on days $0,15,30$ and 45 . The study was conducted after obtaining approval from the institute ethical committee for subjecting the animal to both heat and nutritional stresses.

\section{Blood collection and plasma separation}

Seven $\mathrm{ml}$ of blood samples were collected at 15 days interval from all four groups at $1400 \mathrm{~h}$ using 20 gauge sterilized needles and plastic syringe from external jugular vein in tubes with heparin anticoagulant. Blood samples were divided into two aliquots. One aliquot was used for estimation of haemoglobin $(\mathrm{Hb})$ and packed cell volume (PCV), while the other was subjected to plasma separation. Plasma was separated from blood by centrifugation at $1465 \mathrm{~g}$ at room temperature for 20 minutes. The plasma was then divided into aliquots in micro centrifuge tubes, and kept frozen at $-20^{\circ} \mathrm{C}$ till further analysis. Plasma samples were used to estimate biochemical and endocrine parameters.

\section{Parameters studied}

Body weight (BW) was recorded at fortnightly interval. Physiological response parameters studied were respiration rate (RR), pulse rate (PR), rectal temperature (RT), sweating rate scrotum, and sweating rate skin. The RR was recorded by counting flank movements/min with the help of a stop watch, from a distance of $5 \mathrm{~m}$ without disturbing the rams. The unit of measurement of RR was in breaths/min. The PR was measured by palpating the femoral artery. For recording the pulse rate, rams were restrained gently and acclimatized for these restraining prior to start of the study. The unit of measurement of PR was in beats/min. RT was recorded using a clinical thermometer by inserting the thermometer by 6-7 cm inside the rectum inclined towards the wall of rectum. The RT was recorded by gently restraining the rams. The unit of measurement of RT was in ${ }^{\circ} \mathrm{F}$. Scrotal and skin sweating rate was measured by the cobalt chloride disc method as described by Schleger and Turner (1965). Sweating rate was measured one time $(1400 \mathrm{~h})$ at scrotum and skin only on day 15, day 30 and day 45 .

$\mathrm{The} \mathrm{Hb}$ and PCV were estimated using whole blood samples by methods as described by Balasubramaniam and Malathi (1992) and Jain (1986) respectively. Plasma glucose was estimated using Span diagnostic kit, India by method as described by Tietz (1976) using the UV-Visible recording Spectrophotometer (UV-160A; Shimadzu Corporation, Japan).

Hormonal parameters such as cortisol (analytical sensitivity was $10 \mathrm{nM}$; the intra-assay and inter-assay coefficient of variations were $5.8 \% \& 9.2 \%$ respectively), $\mathrm{T}_{3}$ (analytical sensitivity $0.1 \mathrm{nmol} / \mathrm{L}$; intra-assay and inter-assay coefficient of variations $3.3 \% \& 8.6 \%$ respectively), and $\mathrm{T}_{4}$ (analytical sensitivity $13 \mathrm{nmol} / \mathrm{L}$; intra-assay and inter-assay coefficient of variations $5.1 \%$ \& $8.6 \%$ respectively), were estimated by radio immuno assay (RIA) using gamma counter (PC-RIA MAS, Stretec, Germany) by a validated RIA kit supplied by Immunotech, France. The hormone parameters were measured only on day 15 , day 30 and day 45 .

\section{Data analysis}

The data was analyzed by 2-way repeated measure analysis of variance. Effect of fixed factors namely treatments (control, heat stress, nutritional stress and combined stress), days (longitudinal time over which experiment was carried out on days $0,15,30$ and 45) and their interaction treatment $x$ day on parameters studied were analyzed. A post hoc analysis was performed using Duncan's multiple range tests for pairwise comparisons. Data was presented as mean \pm SEM and statistical analysis was carried out using SPSS software, version 15.0. Level of statistical significance was set at $\mathrm{P}<$ 0.05 .

\section{Results}

\section{Physiological responses}

Body weight recorded showed significant $(\mathrm{P}<0.01)$ variation between the groups with highest $\mathrm{BW}$ recorded in CON while lowest in CS group (Fig. 1A). Generally the trend of BW was in declining phase in all stress groups as the experiment progressed (Fig. 1A). Respiration rate differed significantly $(\mathrm{P}<0.01)$ both during morning and afternoon. The highest $(\mathrm{P}<0.01) \mathrm{RR}$ in morning was recorded in $\mathrm{CON}$ while in the afternoon it was recorded in HS and CS (Fig. 1B). Generally the RRM gradually lowered in all stress groups (HS, NS and CS) as the experiment progressed. However in the afternoon, both HS and CS significantly $(\mathrm{P}<0.01)$ increased RRA on day 15 and this increase reduced gradually as the experiment progressed (Fig. 1C). Both heat stress and nutritional stress did not influence PRM (Fig. 1D). However, the treatments significantly $(\mathrm{P}<0.05)$ influenced PRA towards 
the end of experiment (Fig. 1E). Rectal temperature also differed significantly both during morning $(\mathrm{P}<0.05)$ and afternoon $(\mathrm{P}<0.01)$ as indicated in Fig. $1 \mathrm{~F}$ and Fig. $1 \mathrm{G}$ respectively. The highest RT was recorded in HS while the lowest being in NS both during morning and afternoon. The treatment did not influence scrotal sweating rate $($ Fig. $1 \mathrm{H})$ and scrotal volume (Fig. 1J) but significantly $(\mathrm{P}<0.01)$ influenced skin sweating rate (Fig. 1I). Further, the experimental days significantly influenced $\mathrm{RR}(\mathrm{P}<0.01)$, $\mathrm{PR}(\mathrm{P}<0.01)$, and $\mathrm{RT}$ $(\mathrm{P}<0.01)$ both during morning and afternoon as well as scrotal volume $(\mathrm{P}<0.01)$. However, the interaction between treatment and experimental days significantly $(\mathrm{P}<0.01)$ influenced only $\mathrm{RR}$ in the afternoon.

\section{Blood biochemical parameters}

Packed cell volume differed significantly $(\mathrm{P}<0.01)$ between the groups. The highest level of PCV was recorded in both CON and CS while the lowest being in HS and NS (Fig. $2 \mathrm{~A})$. Blood $\mathrm{Hb}$ also differed significantly $(\mathrm{P}<0.05)$ between the groups. The highest level of $\mathrm{Hb}$ was recorded in both $\mathrm{CON}$ and CS while the lowest being in HS and NS (Fig. 2B). Plasma glucose level also differed significantly $(\mathrm{P}<0.05)$ between the groups. The highest level of plasma glucose was recorded in both CON and HS while the lowest being in both NS and CS (Fig. 2C). Further, experimental days significantly influenced PCV $(\mathrm{P}<0.05), \mathrm{Hb}(\mathrm{P}<0.05)$ and plasma glucose $(\mathrm{P}<0.01)$. However, the interaction between treatment and experimental days did not influence any of the blood biochemical parameters.

\section{Endocrine parameters}

The level of plasma cortisol in the experimental groups showed highly significant $(\mathrm{P}<0.01)$ changes for the treatments (Fig.3A). The highest plasma cortisol concentration was recorded in HS while lowest being in CON rams. The level of plasma $T_{3}$ also showed highly significant $(P<0.01)$ changes among the groups for the treatments (Fig.3B). The highest plasma $T_{3}$ concentration was recorded in CON while lowest being in CS rams. This trend was similar throughout the study period. A similar trend to that of $\mathrm{T}_{3}$ was obtained for the level of plasma $\mathrm{T}_{4}$ with the highest plasma $\mathrm{T}_{4}$ concentration recorded in $\mathrm{CON}$ while lowest being in $\mathrm{CS}$ rams (Fig.3C). However, both the experimental days and interaction between group and experimental days did not influence any of the endocrine parameters.
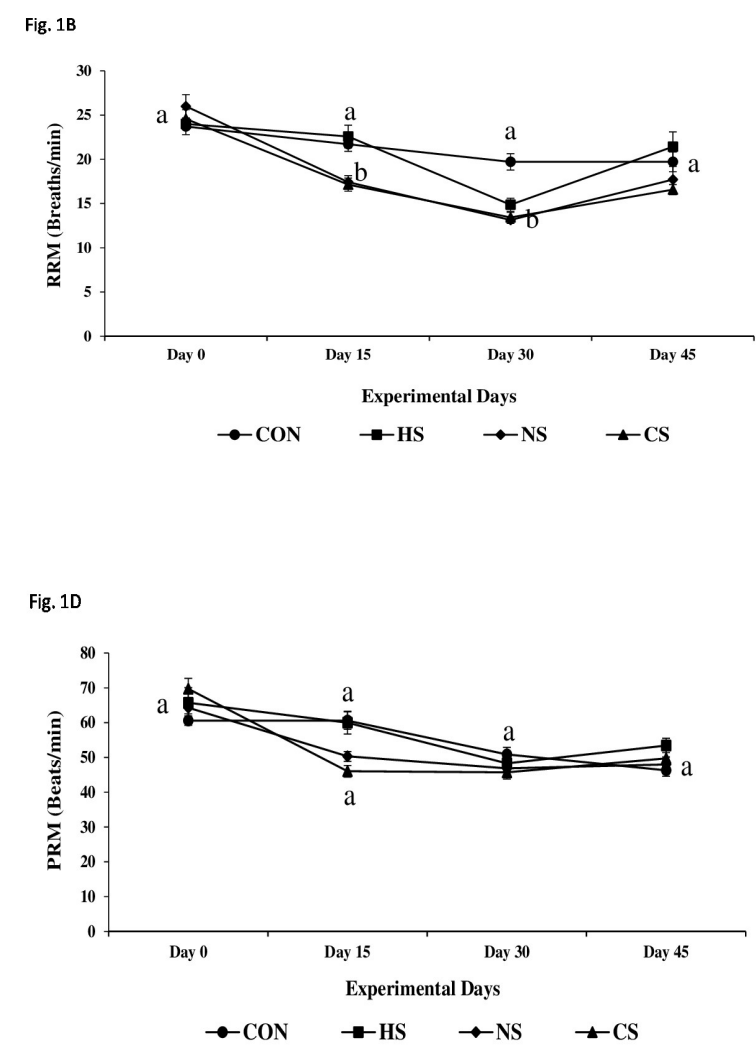
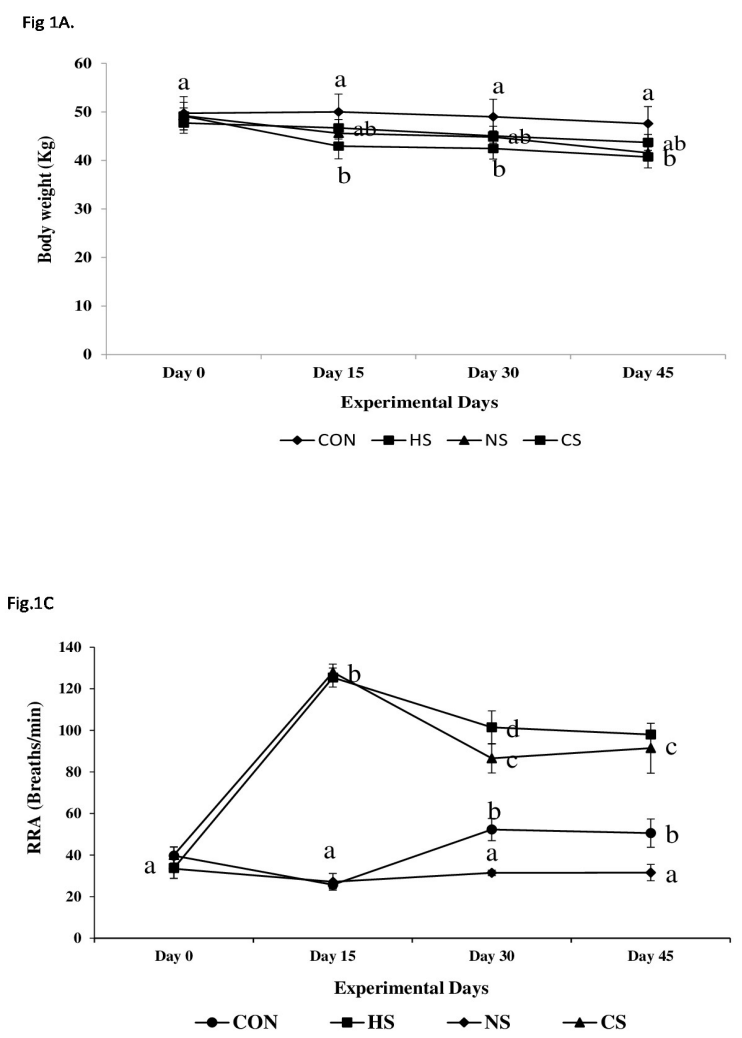
Fig. 1E

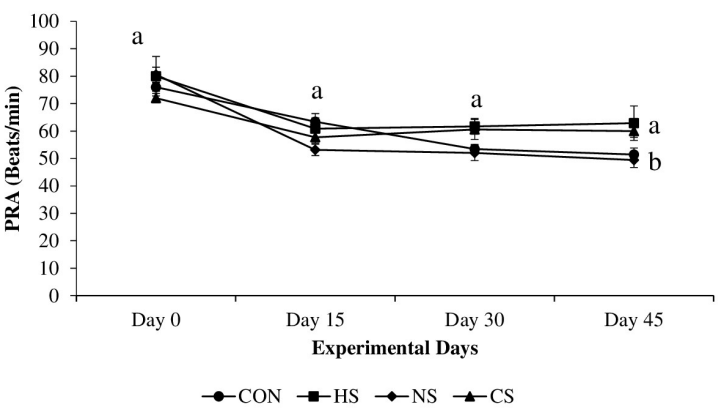

Fig. 1G

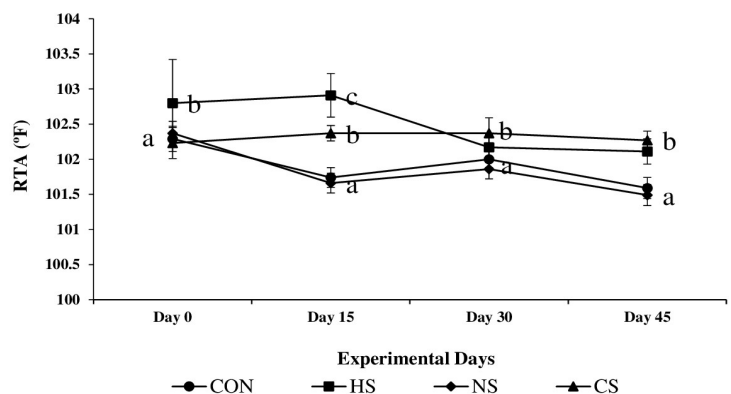

Fig. 11

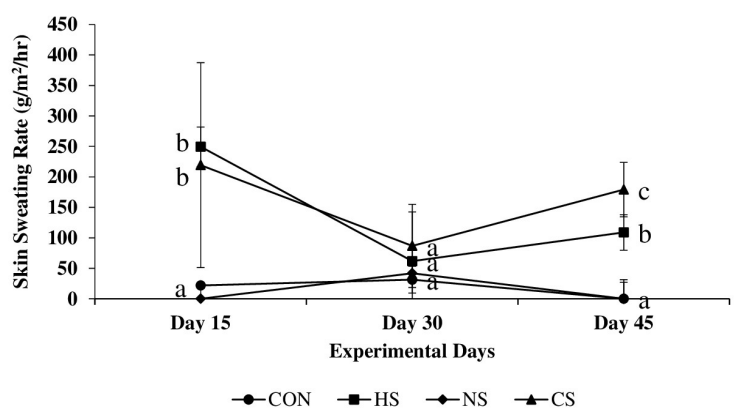

Fig. 1F

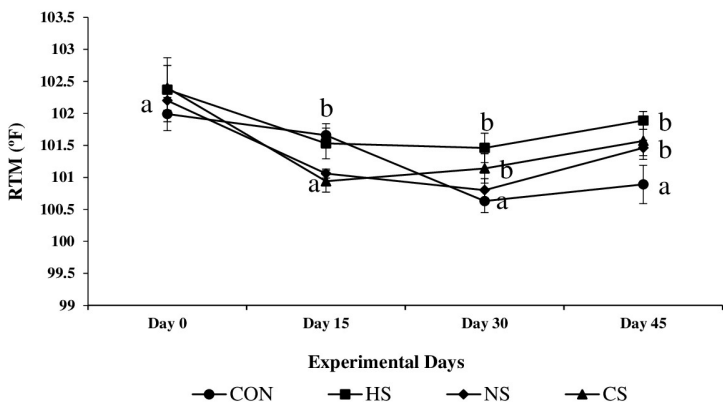

Fig. $1 \mathrm{H}$

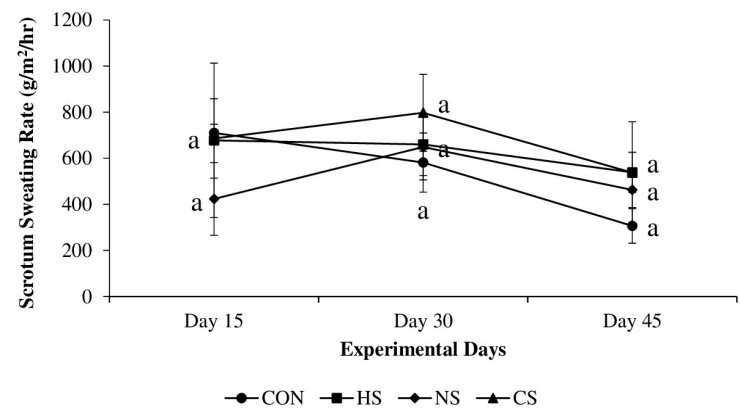

Fig. 1J

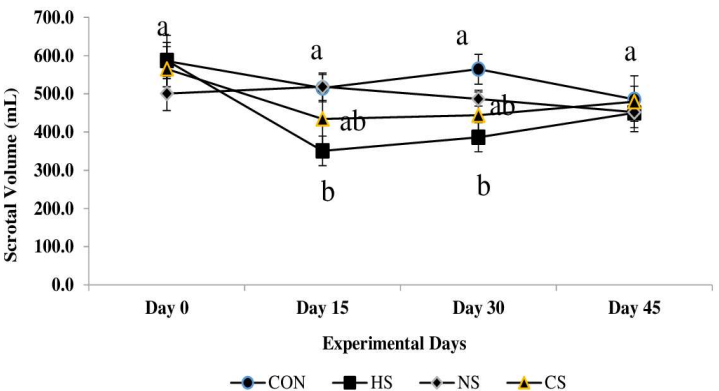

Figure 1 Graphical representation of all physiological variables such as body weight (Fig.1A); RRM (Fig.1B); RRA (Fig.1C); PRM (Fig.1D); PRA (Fig.1E); RTM (Fig.1F); RTA (Fig.1G); ScrSR (Fig.1H); SSR (Fig.1I); and Scrotal volume (Fig.1J) in control, heat stress, nutritional stress and combined stress group Malpura rams. The values having different alphabets within a day differ significantly at $\mathrm{P}<0.05$. RRM-Respiration rate morning; RRA-Respiration rate afternoon; PRM-Pulse rate morning; PRA-Pulse rate afternoon; RTMRectal temperature morning; RTA-Rectal temperature afternoon; ScrSR-Scrotum sweating rate; SRR-Skin sweating rate.

\section{Discussion}

Physiological responses are the first attempt by which an animal tries to cope up to any adverse environmental condition. Heat stress seems to be the important environmental factor influencing RR in this study. Similar heat stress induced increase in respiration rate has been reported in sheep after subjecting them to climatic chamber (Al-Haidary et al 2004). It is known that sheep that are exposed to high ambient temperatures, auguments the efforts to dissipate body heat, resulting in the increase of RR (Marai et al 2007). The RR decreased in feed restricted rams which are similar to the report by Umesiobi et al (2005) in West
African dwarf sheep. The reason for the higher respiration rate in HS rams as compared to NS could be attributed to the higher feed intake in HS rams. This should have provided the extra energy needed for higher respiratory muscular activity in these rams so that they could counter the heat stress effectively by respiratory evaporative cooling mechanisms. This signifies the importance of providing optimum nutrition to counter heat stress in semi-arid tropical environment. Further, the significantly higher RR in CS rams in equivalence with HS rams shows that these rams possess extreme adaptive capability to increase their RR. This finding contradicts our previous findings of lower RR in CS group as compared to HS 
group ewes of same Malpura breed (Sejian et al 2010). The significant impact of both heat and nutritional stress on pulse rate shows that PR is another adaptive mechanisms exhibited by these rams to adapt to these stresses. The increase in PR after heat stress exposure was attributable to increase blood flow from the core to the surface to facilitate the heat loss by sensible and insensible means (Sejian et al 2010). The significantly less PR in CS rams as compared to HS during morning might be due to decrease in the metabolic rate as a result of restricted feeding in this group of animals. This view was supported by the findings of Barkai et al (2002) who reported that there is a correlation between heart rate and metabolic heat production in sheep. Rectal temperature has been shown to be a good indicator of heat stress and may be used to assess the adversity of the thermal environment in sheep and goat (Marai et al 2002; Daramola and Adeloye 2009). There were no significant changes in RT between HS and CS groups in this study. This finding is again contradictory to the previous finding in ewes of the same breed which reported that RT significantly reduced in CS group as compared to heat stress group (Sejian et al 2010). The nonsignificant difference in RT and sweating rate between HS and CS indicates that the Malpura rams were adjusting their biological systems to cope up to two stresses simultaneously. Further, the non-significant interaction between treatments and experimental days on the physiological parameters except RRA indicates that the effect of HS, NS and CS persisted over the entire period of study on these parameters. This was in contrast to the female study conducted in our laboratory and this indicate on comparative basis Malpura rams experienced less physiological strain as compared to that of ewes in the previous study (Sejian et al 2010) of the same breed. This difference in physiological responses between males and females indicates that there could be a gender difference in adaptive capability in Malpura breed of sheep. The significant interaction between treatments and experimental days on RRA indicates that these animals are trying to adapt to the situation by altering their respiration rate.

The higher PCV values during heat stress condition has been reported to be an adaptive mechanism to provide water necessary for evaporative cooling process during heat stress condition in sheep (Al-Haidary 2004). The higher PCV in CS group as compared to HS and NS groups was again contradictory finding to the previous study in ewes which reported significantly lower PCV in combined stress group as compared to heat and nutritional stress groups (Sejian et al 2010). This significant reduction in PCV level in CS rams as compared to $\mathrm{CON}$ could be attributed to the severe dehydration as a result of both heat stress and increased respiratory evaporative cooling and sweating mechanisms in these rams. Although CS group also was subjected to nutritional restriction but still the level of $\mathrm{Hb}$ was significantly higher than NS rams.

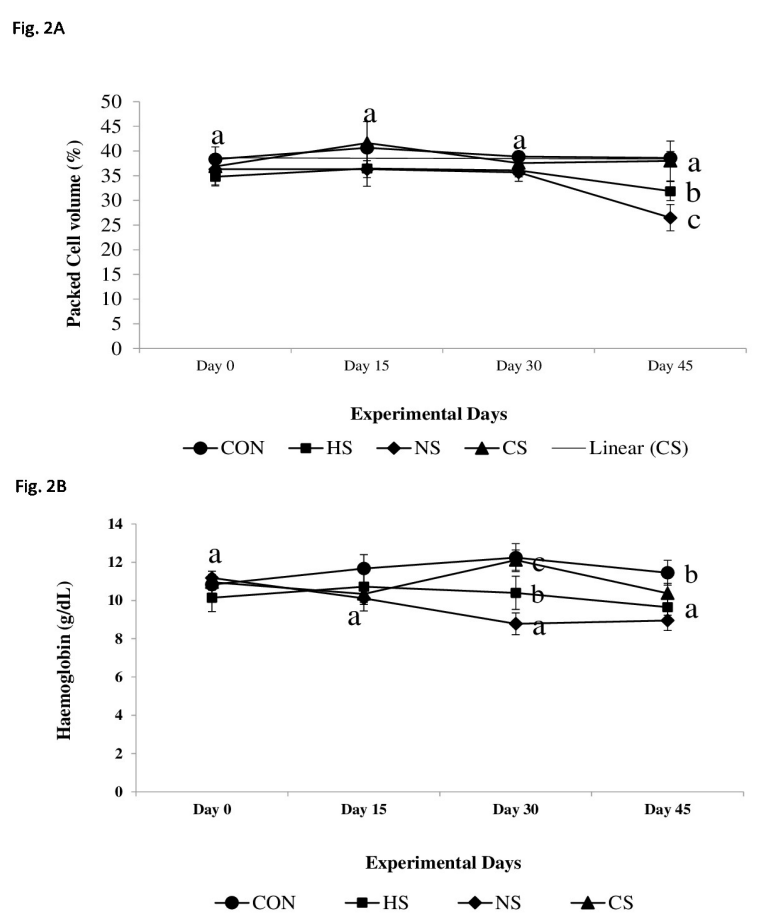

Fig. 2C

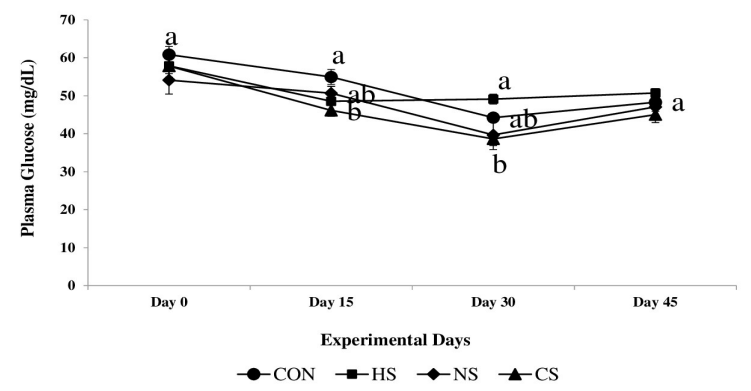

Figure 2 Graphical representation of blood variables such as packed cell volume (Fig.2A); haemoglobin (Fig.2B) and plasma glucose (Fig.2C) in control, heat stress, nutritional stress and combined stress group Malpura rams. The values having different alphabets within a day differ significantly at $\mathrm{P}<0.05$.

However, in contrast to our findings, Broucek et al (2009) reported that heat stress had no negative effect on hematological parameters in calves. But McManus et al (2009) reported a strong positive correlation between PCV and $\mathrm{Hb}$ concentration, indicating the significance of these parameters for heat tolerance in Brazilian sheep. The very high concentration of $\mathrm{Hb}$ in CS group as compared to HS and NS group rams could be attributed to the fact that these animals need more $\mathrm{Hb}$ to carry oxygen molecules to support the evaporative cooling mechanism. This again shows the superior adaptive capability of Malpura rams for the combined stresses. The lowest plasma glucose concentration in CS rams shows the energy requirement was more in combined stress group as compared to individual stress groups. Since the thermoregulatory mechanisms are more active in CS group the energy demand was huge in this group to support the life sustenance activities. Several researchers have studied the effect of thermal stress on blood glucose concentrations but 
conflicting results have been reported (More and Sahni 1980; Habeeb 1987; Sejian and Srivastava 2010). The decrease in plasma glucose could also be due to the marked dilution of blood or increase in plasma glucose utilization to produce more energy for the greater muscular expenditure required for high muscular activity (Naqvi and Hooda 1991; Rasooli et al 2004). Further, the decrease in glucose level during heat exposure could be related to decrease in concentration of thyroid hormones in the present study, which are closely associated to energy metabolism during heat exposure. The increased glucose utilization due to increased respiratory muscular activity after thermal exposure could have resulted in more reduction in glucose concentration in combined stress group. Further, the non-significant interaction between treatments and experimental days on all biochemical parameters indicates that the effect of HS, NS and CS persisted over the entire period of study on these parameters. These findings further strengthen the fact that male possess superior adaptive capability than females in Malpura breed of sheep.

The association between thermal stress and increased secretion of cortisol, the principal glucocorticoid hormone in small ruminants, is well documented (Ali and Hayder 2008). One would have expected the plasma cortisol concentration to be significantly higher in CS group as these rams were exposed to two stresses simultaneously. But the level of cortisol concentration was significantly lower in CS as compared to HS. This difference could be attributed to the nutritional deficiency in CS rams. Similar result was reported in Malpura ewes by Sejian et al (2010). Further, cortisol is thermogenic in nature and its action will contribute to additional heat load (Alvarez and Johnson 1973) and hence these combined stressed animals have the capability to adjust the cortisol level to minimum possible increase to elicit the heat stress relieving effects. Hence plasma cortisol may be considered as an important biological marker for combined stresses in Malpura rams. Both heat stress and nutritional stress in general are associated with significant depression in thyroid gland activity resulting in lowering of thyroid hormones level (Nazifi et al 2003; Rasooli et al 2004; Sejian et al 2014). The significantly lower level of plasma thyroid hormone concentrations in CS rams in the present study could be attributed to the combined effects of both heat and nutritional stress in CS rams. Hence both $\mathrm{T}_{3}$ and $\mathrm{T}_{4}$ may also be considered as ideal biological markers for combined stresses in Malpura rams. Further, the non-significant interaction between treatments and experimental days on all endocrine parameters indicates that the effect of HS, NS and CS persisted over the entire period of study on these parameters. This shows that Malpura rams heavily relied on endocrine mechanisms to adapt to HS, NS and CS.
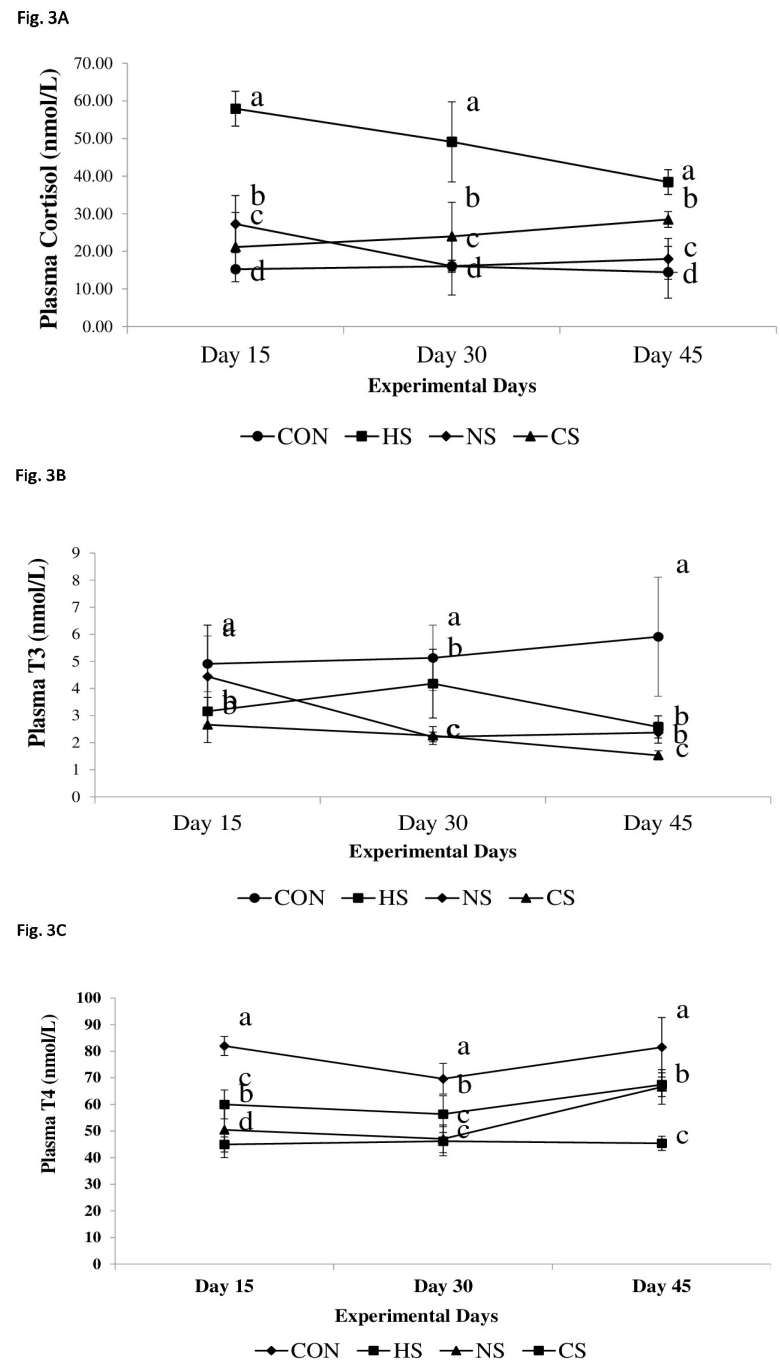

Figure 3 Graphical representation of endocrine variables such as plasma cortisol (Fig.3A); plasma T3 (Fig.3B) and plasma T4 (Fig.3C) in control, heat stress, nutritional stress and combined stress group Malpura rams. The values having different alphabets within a day differ significantly at $\mathrm{P}<0.05$.

\section{Conclusions}

The findings from the study indicate that Malpura rams subjected to HS and NS separately had less detrimental effects on ram's adaptive capability. However, when both these stresses were coupled in CS group, it had serious consequences on adaptive capability of these rams. Hence, it is very pertinent to conclude that when two stressors occur simultaneously, the total impact on biological functions necessary to adapt to the stressful conditions may be severe. Further it is inferred that males might possess superior adaptive capability than females in Malpura breed of sheep.

\section{Acknowledgements}

The authors are highly thankful to Indian Council of Agricultural Research for funding this project. The authors also thankful to the Director of Central Sheep and Wool Research Institute for providing the research facilities and to Shri K.C. Sharma for his technical help during the experiment. 


\section{References}

Al-Haidary AA (2004) Physiological responses of Naimey sheep to heat stress challenge under semi-arid environments. International Journal of Agricultural Biology 2:307-309.

Ali A, Hayder M (2008) Seasonal variation of reproductive performance, foetal development and progesterone concentrations of sheep in the subtropics. Reproduction in Domestic Animals 43:730734 .

Alvarez MB, Johnson HD (1973) Environmental heat exposure on cattle plasma catecholamines and glucocorticoids. Journal of Dairy Science 56:189-194.

Balasubramaniam P, Malathi A (1992) Comparative study of hemoglobin estimated by Drabkin's and Sahli's methods. Journal of Postgraduate Medicine 38:8-9.

Barkai D, Landau S, Brosh A, Baram H, Molle G (2002) Estimation of energy intake from heart rate and energy expenditure in sheep under confinement or grazing condition. Livestock Production Science 73:237-246.

Broucek J, Kisac P, Uhrincat M (2009) Effect of hot temperatures on the hematological parameters, health and performance of calves. International Journal of Biometeorology 53:201-208.

Daramola JO, Adeloye AA (2009) Physiological adaptation to humid tropics with special references to the West African Dwarf (WAD) goat. Tropical Animal Health and Production 41:1005-1016.

Habeeb AA (1987) The role of insulin in improving productivity of heat-stressed farm animals with different techniques. $\mathrm{PhD}$ thesis. Faculty of Agriculture, Zagazig University, Zagazig, Egypt.

Hatfield J, Boote K, Fay P, Hahn LC, Izaurralde BA, Kimball T, Mader J, Morgan D, Ort W, Polley A, Thomson WD (2008) Agriculture. In: The effects of climate change on agriculture, land resources, water resources, and biodiversity in the United States. A Report by the U.S. Climate Change Science Program and the Subcommittee on Global Change Research. Washington, DC., USA, pp 362.

Jain NC (1986) Schalm's Veterinary Haematology. Lea and Febiger, Philadelphia.

Marai IFM, El-Darawany AA, Fadiel A, Abdel-Hafez MAM (2007) Physiological traits as affected by heat stress in sheep. Small Ruminants Research 71:1-12.

Marai IFM, Habeeb AAM, Gad AE (2002) Reproductive traits of female rabbits as affected by heat stress and light regime, under subtropical conditions of Egypt. Journal of Animal Science 75:451-458.

McManus C, Paludo GR, Louvandini H, Gugel R, Sasaki LCB, Paiva SR (2009) Heat tolerance in Brazilian sheep: physiological and blood parameters. Tropical Animal Health and Production 41:95-101.

Moberg GP (2000) Biological responses to stress. Implications for animal welfare. In: Moberg GP, Mench JP (eds), Biology of animal stress, CAB International, Wallingford, UK.

Naqvi SMK, Hooda, OK (1991) Influence of thermal, nutritional and exercise stress on some blood parameters of native and crossbred sheep. Indian Journal of Animal Science 61:660-662.

Nazifi S, Saeb M, Rowghani E, Kaveh K (2003) The influence of thermal stress on serum biochemical parameters of Iranian fat-tailed sheep and their correlation with triiodothyronine $\left(\mathrm{T}_{3}\right)$, thyroxine $\left(\mathrm{T}_{4}\right)$ and cortisol concentrations. Comparative Clinical Pathology 12:135139.
Rasooli A, Nouri M, Khadjeh GH, Rasekh A (2004) The influence of seasonal variations on thyroid activity and some biochemical parameters of cattle. Iranian Journal of Veterinary Research 5:13831391.

Schleger AV, Turner HG (1965) Sweating rates of cattle in the field and their reaction to diurnal and seasonal changes. Australian Journal of Agricultural Research 16:92-106.

Sejian V, Srivastava RS (2010) Effects of melatonin on adrenal cortical functions of Indian goats under thermal stress. Veterinary Medicine International doi:10.4061/2010/348919

Sejian V, Maurya VP, Naqvi SMK (2010) Adaptability and growth of Malpura ewes subjected to thermal and nutritional stress. Tropical Animal Health and Production 42:1763-1770.

Sejian V, Maurya VP, Naqvi SMK (2010) Adaptive capability as indicated by endocrine and biochemical responses of Malpura ewes subjected to combined stresses (thermal and nutritional) under semiarid tropical environment. International Journal of Biometeorology 54:653-661

Sejian V, Maurya VP, Naqvi SMK (2011) Effect of thermal, nutritional and combined (thermal and nutritional) stresses on growth and reproductive performance of Malpura ewes under semi-arid tropical environment. Journal of Animal Physiology and Animal Nutrition 95:252-258.

Sejian V, Maurya VP, Kumar K, Naqvi SMK (2013) Effect of multiple stresses (thermal, nutritional and walking stress) on growth, physiological response, blood biochemical and endocrine responses in Malpura ewes under semi-arid tropical environment. Tropical Animal Health and Production 45:107-116.

Sejian V, Bahadur S, Naqvi SMK (2014) Effect of nutritional restriction on growth, adaptation physiology and estrous responses in Malpura ewes. Animal Biology 64:189-205.

St-Pierre NR, Cobanov B, Schnitkey G (2003) Economic losses from heat stress by US livestock industries. Journal of Dairy Science 86:52-77.

Tietz NW (1976) Clinical guide to Laboratory Tests, W.B. Saunders Co., Philadelphia.

Umesiobi DO, Iloeje MU, Ibokwe IO, Berepubo NA, Imumorin IG (2005) Physiological and biochemical responses of West African dwarf sheep to partial feed restriction. Indian Journal of Animal Science 75:956-960. 